\title{
Convergence Patterns in Sovereign Bond Yield Spreads: Evidence from the Euro Area
}

\author{
Nikolaos Antonakakis*, Christina Christou^, Juncal Cunado` and Rangan Gupta*
}

\begin{abstract}
This study examines the convergence patterns of Euro Area (EA) 17 countries' sovereign bond yield spreads (relative to German bund) over the period of March 2002 to December 2015, by employing the convergence algorithm developed by Phillips and Sul (2007). The empirical findings suggest rejection of full convergence across the EA17 countries' bond yields spreads, and the presence of a certain number of clubs. In particular, three subgroup convergence clubs emerge, with Cyprus, Spain, France, Greece, Ireland, Lithuania, Luxembourg, Latvia, Portugal and Slovenia in the first; Belgium, Italy and Malta in the second; and Austria, Finland, Netherlands and Slovakia in the third club. Moreover, there is also evidence that the first two clubs could be merged to form a larger convergence club. The transitional curves indicate that, despite short-run divergences, EU17 sovereign bond yield spreads tend to converge in the long-run, with the exception of those in Greece and Cyprus, indicating the strong attempts of most of the countries under investigation to adopt fiscal policies that eventually contribute to a convergence pattern.
\end{abstract}

JEL Classification: C33; E61; G12; H77

Keywords: Sovereign bond yield spreads; Club convergence; Euro Area

\footnotetext{
* Corresponding author. Webster Vienna Private University, Department of Business and Management, 1020, Vienna, Austria. Email: nikoalos.antonakakis@webster.ac.at. Tel: +43-1-2699293-4354. University of Portsmouth, Economics and Finance Group, PO1 3DE, Portsmouth, United Kingdom. Email: nikolaos.antonakakis@port.ac.uk. Tel: +44 (0)23 9284 4261.

- Open University of Cyprus, School of Economics and Management, Giannou Kranidioti 56, 2220 Latsia, Cyprus. christou@unipi.gr

- University of Navarra, School of Economics, Edificio Amigos, E-31080 Pamplona, Spain. Email: jcunado@,unav.es. Juncal Cuñado gratefully acknowledges financial support from the Ministerio de Economía y Competitividad (ECO2014-55496).

* University of Pretoria, Department of Economics, Pretoria, 0002, South Africa. Email: rangan.gupta@up.ac.za.
} 


\section{Introduction}

Since the global financial and economic crisis, and the subsequent Euro Area (EA) sovereign debt crisis, euro area sovereign yield spreads have diverged considerably. As these spreads are important measures of governments' relative financing conditions, they have become the focus of public attention.

Prior to the European Monetary Union (EMU) in 1999, sovereign bond yields in the euro area showed a strong convergence process, driven not only by the anticipation of the entrance of the euro and the corresponding elimination of intra-euro area exchange rate risk (European Central Bank, 2003), but by other variables as well, such as the harmonization of fiscal and monetary policies inherent to the unification process (Côté and Graham, 2004). This convergence process was followed by a period of low Eurozone yield spreads (e.g. in March 2002, the 10-year yield spreads to the German Bunds were practically zero in the EA countries, with Slovenia, which had not adopted the euro yet ${ }^{1}$, presenting a maximum spread of 4.5 percentage points). Then, sovereign yield spreads rose dramatically since 2009, when the maximum yield spreads were those of Lithuania (11\%) and Latvia (7.6\%), countries that were not yet in the EA. With the intensification of the sovereign debt crisis, sovereign yield spread diverged significantly, reaching maximum values in Greece (27\%) and Portugal $(11 \%)$ in February 2012.

The adoption of a common currency was expected to improve the convergence process of bond yields and to reduce sovereign yield spreads, as the exchange rate risk was eliminated. However, besides the currency risk, the literature has also attributed the differences in the yield spreads to both international factors (such as general risk perception) and domestic factors (liquidity and sovereign

\footnotetext{
1 There are currently 19 EU member states in the Eurozone, of which the first 11 (Austria, Belgium, Finland, France, Germany, Ireland, Italy, Luxembourg, Netherlands, Portugal and Spain) introduced the euro in January of 1999. Greece adopted the euro in January 2001, and the following seven countries joined the Eurozone in the last decade: Slovenia (in 2007), Cyprus and Malta (in 2008), Slovakia (in 2009), Estonia (in 2011), Latvia (in 2014) and Lithuania (in 2015).
} 
risk). Empirical literature (e.g. Codogno et al., 2003; Geyer et al., 2004; Favero et al., 2010; Pozzi and Wolswijk, 2009; Bernoth and Erdogan, 2012) shows that international risk factors have a significant effect on yield spreads in EMU countries, which explains why in times of economic uncertainty and crisis periods it is more likely to observe wider spreads since investors typically have a higher preference for less risky and more liquid assets (Barrios et al., 2009). Second, and as far as the domestic factors are concerned, investors will demand compensation for not investing in secure (credit risk compensation) and liquid (liquidity risk compensation) bonds. Empirical literature on determinants of sovereign yield spreads also shows a significant impact of a credit risk component (linked to government fiscal deficits and the stock of government debt as a share of GDP), while the impact of liquidity is significant in some papers (Favero et al., 2010) and not significant in others (Oliveira et al., 2012; Codogno et al., 2003).

Moreover, the literature has also documented the possibility that certain yield spreads could also be driven by a contagion component, defined in the literature as a significant increase in comovements across countries (conditional on a crisis in one of them) that cannot be explained by the country fundamentals (Masson, 1999). Most of the literature on contagion during the sovereign risk crisis in the Eurozone finds strong evidence of contagion (Amisano and Tristani, 2011; Favero and Missale, 2012; Calice et al., 2012; Antonakakis and Vergos, 2013). Furthermore, the results suggest that Greece, Ireland and Portugal are the main sources of contagion effects (Metiu, 2012; Arghyrou and Kontonikas, 2012; Beirne and Fratzscher, 2013; Gomez-Puig and Sosvilla-Rivero, 2014), followed by Italy and Spain (Leschinski and Bertram, 2013).

The implications of the above literature on the convergence of sovereign bond yield spreads will depend on the relative importance of the international factor and country-specific factors in determining the bond yield differentials, as well as on the possibility of contagion effects. However, 
despite of the vast literature on the determinants of sovereign bond yield spreads in EU countries, there is not yet any consensus reached on the relative importance of the previous mentioned factors in explaining sovereign bond yield differentials. Furthermore, most of the studies have found that the relative impact of each of these variables (international risk perception, liquidity, credit risk, contagion effect) on the spreads varies over time. For example, Bernoth and Erdogan (2012) analyse the determinants of sovereign yield spreads for 10 Eurozone countries for the period 1999- 2010, and find that the impact of fiscal variables and the global risk factor on yield spreads varies considerably over time. Afonso et al. (2015) study a panel of 10 EA countries to assess the determinants of government bond yields, suggesting that the impact of these determinants has also changed over time since investors, for example, penalise countries' fiscal imbalances more strongly since 2009. Sgherri and Zoli (2009) assess the determinants of spreads between 10 EA countries and Germany for the period 2003-2009 and find that EA sovereign risk premium differentials were mainly driven by a common international factor until 2008, when the country specific sovereign risk became more important. According to Sgherri and Zoli (2009), this explains the evidence of convergence in bond yield spreads observed before the crisis and the divergence patterns found during the crisis period.

Another strand of the literature has tested for convergence ${ }^{2}$ in bond yield spreads by studying the time series properties of the bond yields differentials using different methodologies. Early studies applied traditional ADF (Dickey and Fuller, 1979) and PP (Phillips and Perron, 1988) unit root tests in order to test whether or not bond yield spreads were stationary (Rose, 1988; Campbell and Shiller,

\footnotetext{
2 The convergence hypothesis has been tested in the literature using different approaches. For example, in a cross section approach, a negative (partial) correlation between a change in a variable (e.g., growth rates) and initial values is interpreted as evidence of (conditional) beta-convergence (e.g., Baumol, 1986; Barro and Sala-i-Martin, 1992; Mankiw et al., 1992). According to the sigma-convergence, convergence holds when the cross section standard deviation of some variables (e.g. bond yield spreads) falls over time (Barro and Sala-i-Martin, 1992; Friedman, 1992). Although most of these tests were developed and have been mostly applied to test for real convergence, they have also been used to test for convergence in bond yields (Baele et al., 2004). In this paper, we follow a time series approach and analyse the time series properties of the bond yields differentials.
} 
1991; Siklos and Wohar, 1997). As new time series econometric techniques were developed, they have also been applied to test for convergence in bond yield spreads. For example, the possible existence of structural breaks in yield spreads has also been taken into account in the literature (e.g. Frömmel and Kruse, 2009), while the persistence in bond yields has also been tested using fractional integration techniques (Baum and Barkoulas, 2006; Sibbertsen et al., 2014). Sibbertsen et al. (2014) examine the persistence in government bond yield spreads in France, Italy and Spain (relative to Germany) over the period 2002-2012 finding evidence of both breaks between 2006 and 2008, and an increase in the persistence of yield spreads after those breaks, coinciding with the sovereign debt crisis. The temporal evolution of the differences in EA bond yield spreads, together with the main results found in the literature justifies the use of the methodology proposed by Phillips and Sul (2007). We postulate that this method represents more realistically the behaviour of the EA countries bond yield spreads, since it includes both global and individual specific components and it is formulated as a nonlinear timevarying factor model.

As such, the objective of the paper is to examine the convergence patterns of 17 EA countries' sovereign bond yield spreads (relative to German bund) over the period of March 2002 to December 2015, by employing the convergence algorithm developed by Phillips and Sul (2007). The main contributions of this paper are the following. First, the sample of countries in the empirical analysis includes $18 \mathrm{EA}$ member states in the Eurozone. The inclusion of the new member states in the analysis (Slovenia, Cyprus, Malta, Slovakia, Estonia, Latvia and Lithuania) is a valuable contribution of this paper, since most of the papers in the literature focus on the countries that first adopted the euro ${ }^{3}$,

\footnotetext{
${ }^{3}$ One exception is the paper by Siklos (2010), who estimates whether the 10 new member states (Cyprus, Malta, Slovenia, Slovakia, Czech Republic, Estonia, Hungary, Lithuania, Latvia and Poland) that joined the EU in 2004 have achieved longterm interest rate convergence. Using quarterly data from the mid-1990s, the results suggest no evidence of convergence in interest rates.
} 
and it could help us understand how the adoption of a common currency affects the bond yields convergence process.

Second, the analysis covers the time period from March 2002 to December 2015, a period of time in which sovereign yield spreads have shown a very heterogeneous behaviour, and which could be divided in different sub-periods (Afonso et al., 2015): the period of low yield spreads preceding the global credit crunch (March 2002- August 2007), the period during which the global credit crunch had not yet mutated into a sovereign debt crisis (August 2007- February 2009), and the last period of our sample including the sovereign debt crisis (March 2009- December 2015). Based on the idea that the degree of convergence or financial integration has been different over the analysed sub-periods, we test for convergence using the non-linear varying coefficients factor model developed by Phillips and Sul (2007), which provides the framework for modelling transitional dynamics as well as long run behaviour. Although the same methodology has already been used in the literature to test for convergence in different variables (see Apergis et al., 2014, for a detailed literature review), to our knowledge, this is the first paper that applies the non-linear varying coefficients factor model developed by Phillips and Sul (2007) to test for convergence in 17 EA countries' bond yield spreads over the period March 2002- December 2015. ${ }^{4}$

Finally, this methodology allows us to endogenously determine the existence of different convergence clubs among the different economies in the sample. The existence of more than one convergence club will imply the rejection of the convergence hypothesis across the 17 countries' bond yield spreads. Furthermore, the existence of different convergence clubs will allow us to classify the 17 EA countries based on their long-run common trend, instead of on the more simplistic

\footnotetext{
${ }^{4}$ A remotely related paper is that of Apergis and Cooray (2014), who used the Phillips and Sul (2007) method to analyse convergence in the sovereign debt ratio of five European Monetary Union (EMU) countries, namely, Cyprus, Greece, Ireland, Italy, Portugal and Spain. The paper finds the evidence of lack of debt convergence for Greece and Portugal, suggesting that there is no uniform austerity prescription for these five economies.
} 
classification "core/periphery countries". The resulting convergence clubs will allow us to classify all the 17 EA countries (while many of them are not included in the "core/periphery" groups), and it will also give us information on how divergent the different convergence clubs are.

The empirical findings suggest rejection of full convergence across the EA17 countries' bond yields spreads, and the presence of a certain number of clubs. In particular, three subgroup convergence clubs emerge, with Cyprus, Spain, France, Greece, Ireland, Lithuania, Luxembourg, Latvia, Portugal and Slovenia in the first; Belgium, Italy and Malta in the second; and Austria, Finland, Netherlands and Slovakia in the third club. Moreover, there is also evidence that the first two clubs could be merged to form a larger convergence club. The transitional curves indicate that, despite shortrun divergences, EU17 sovereign bond yield spreads tend to converge in the long-run, with the exception of those in Greece and Cyprus, indicating the strong attempts of most of the countries under investigation to adopt fiscal policies that eventually contribute to a convergence pattern.

The remainder of this paper is organised as follows. Section 2 describes the econometric methodology and the data used. Section 3 presents and discusses the empirical results. Finally, Section 4 summarizes and concludes this study.

\section{Methodology and Data}

\subsection{Econometric Methodology}

In this section, we outline the methodology proposed by Phillips and Sul (2007) (henceforth PS) to test for convergence in a panel of countries and to identify any convergence clubs. PS propose a new econometric approach for testing the convergence hypothesis and the identification of convergence clubs. Their method uses a nonlinear time-varying factor model and provides the framework for 
modeling transitional dynamics as well as long run behavior. Furthermore, their statistical methodology can test for convergence in economic variables other than output.

Let $y_{i t}$ denote a time series index $i$ at time $t$. The new methodology adopts the following simple time-varying common-factor representation for $y_{i t}$ of country $i$ :

$$
y_{i t}=\delta_{i t} \mu_{t}
$$

where $\mu_{t}$ is a single common component and $\delta_{i t}$ is a time-varying idiosyncratic element that captures the deviation of country $i$ from the common path defined by $\mu_{t}$. Within this framework, all $\mathrm{N}$ countries will converge, at some point in the future, to the steady state, if $\lim _{k \rightarrow \infty} \delta_{i t+k}=\delta$ for all $i=1$, $2, \ldots, N$, irrespective of whether countries are near the steady state or in transition. This is important given that the paths to the steady state (or states) across countries can differ significantly.

The goal of PS is to test whether economic variables $y_{i t}, \mathrm{i}=1,2, \ldots, \mathrm{N}$ tend to converge to a single steady state as $t \rightarrow \infty$. To this direction they adopt a factor representation $y_{i t}=\delta_{i t} \mu_{t}$ (eq. 1) for each economic variable in the sample. The factor $\mu_{t}$ is assumed common across individuals (economies), while the transition dynamics are captured by the idiosyncratic components $\delta_{i t}$ which are allowed to vary across cross section and time. Convergence is a dynamic process. Since $\delta_{i t}$ trace out the transition paths, convergence can be tested by examining the temporal relative evolution of $\delta_{i t}$. PS do not assume any parametric form for $\mu_{t}$; they just factor it out and they concentrate on $\delta_{i t}$

Since we cannot directly estimate $\delta_{i t}$ from equation (1) due to over-parameterization, i.e. the number of parameters is greater than the number of observations, PS assume a semiparametric form 
for $\delta_{i t}$, which enables them to construct a formal test for convergence. In particular, they eliminate the common component $\mu_{t}$ through rescaling by the panel average:

$$
h_{i t}=\frac{y_{i t}}{\frac{1}{N} \sum_{i=1}^{N} y_{i t}}=\frac{\delta_{i t}}{\frac{1}{N} \sum_{i=1}^{N} \delta_{i t}} .
$$

The relative measure $h_{i t}$ captures the transition path with respect to the panel average. Defining a formal econometric test of convergence as well as an empirical algorithm of defining club convergence requires the following assumption for the semi-parametric form for the time-varying coefficients $\delta_{i t}$ :

$$
\delta_{i t}=\delta_{i}+\sigma_{i t} \xi_{i t}
$$

where $\sigma_{i t}=\frac{\sigma_{i}}{L(t) t^{\alpha}}, \sigma_{i}>0, t \geq 0$, and $\xi_{i t}$ is weakly dependent over $t$, but iid(0,1) over $i$. The function $L(t)$ varies slowly, increasing and diverging at infinity. ${ }^{5}$ The presence of $L(t)$ ensures that $\delta_{i t} \stackrel{p}{\rightarrow} \delta_{i}$ as $t \rightarrow \infty$ and $\alpha \geq 0$. In the model (1)-(3) and under this specific form for $\sigma_{i t}$, convergence and divergence conditions can be expressed as follows:

Convergence $\left(\mathcal{H}_{\mathbf{0}}\right):$ plim ${ }_{k \rightarrow \infty} \delta_{i t+k}=\delta$ if and only if $\delta_{i}=\delta$ and $\alpha \geq 0$,

Divergence $\left(\mathcal{H}_{\boldsymbol{A}}\right): \operatorname{plim}_{k \rightarrow \infty} \delta_{i t+k} \neq \delta$ if and only if $\delta_{i} \neq \delta$ or $\alpha<0$.

To define a formal test for the convergence hypothesis, PS construct the cross sectional variance ratio $H_{1} H_{t}$, where $H_{t}=\frac{1}{N} \sum_{i=1}^{N}\left(h_{i t}-1\right)^{2}$ and $h_{i t}$ is defined in equation (2). Under the convergence

\footnotetext{
${ }^{5}$ In this paper, following PS, we set $L(t)=\log t$. The authors (PS)) show that the choice $\mathrm{L}(\mathrm{t})=\log (\mathrm{t})$ is preferred in terms of asymptotic power. Additionally, they found that this choice of $\mathrm{L}(\mathrm{t})$ works well in simulations and is recommended for empirical applications. In general, any similar increasing slowly varying function can be used.
} 
hypothesis, $h_{i t} \rightarrow 1$ and $H_{t} \rightarrow 0$ as $t \rightarrow \infty$ for given N. PS show that $H_{t}$ has the following analytic form: ${ }^{6}$

$$
\log H_{t}=-2 \log L(t)-2 \alpha \log t+2 \log \frac{v_{\psi N}}{\delta}+\epsilon_{t}
$$

with

$$
\epsilon_{t}=\frac{1}{\sqrt{N}} \frac{\eta_{N t}}{v_{\psi N}^{2}}-\frac{2}{\delta} \frac{1}{t^{\alpha} L(t)} \psi_{t}+\frac{1}{\delta^{2}} \frac{1}{t^{2 \alpha} L(t)^{2}} \psi_{t}^{2}+O_{p}\left(\frac{1}{N}\right)
$$

where $v_{\psi N}^{2}=N^{-1}\left(1-N^{-1}\right) \sum_{i=1}^{N} \sigma_{i}^{2} \rightarrow v_{\psi}^{2} \quad$ as $\quad N \rightarrow \infty, \quad \eta_{N t}=N^{-1 / 2} \sum_{i=1}^{N} \sigma_{i}^{2}\left(\xi_{i t}^{2}-1\right)$, and $\psi_{t}=N^{-1} \sum_{i=1}^{N} \sigma_{i t} \xi_{i t}$. From (4) the following simple regression can be deduced:

$$
\log \frac{H_{1}}{H_{t}}-2 \log L(t)=c+b \log t+u_{t}
$$

where $b=2 \alpha, u_{t}=-\epsilon_{t}$, and the intercept $c=\log H_{1}-2 \log \frac{v_{\psi N}}{\delta}=-2 \log L(1)+u_{1}$ does not depend on $\alpha$. Under convergence, $\log \left(H_{1} / H_{t}\right)-2 \log L(t)$ diverges to $\infty$ (as $2 \log L(t)$ when $\alpha=0$, or as $2 \alpha \log t$ when $\alpha>0)$. Note that divergence of $\log \left(H_{1} / H_{t}\right)$ corresponds to $H_{t} \rightarrow 0$ as $\rightarrow \infty$. Thus the null hypothesis of convergence, takes the form: $\mathcal{H}_{\mathbf{0}}: \alpha \geq 0$ and can be tested using a simple one sided t test. Under the divergence hypothesis $\boldsymbol{H}_{\boldsymbol{A}}$, PS show that, $H_{t}$ converges to a positive quantity as $t \rightarrow \infty$ and the dependent variable in (5), $\log \left(H_{1} / H_{t}\right)-2 \log L(t)$ diverges to $-\infty$. Hence, the $t$ test on the coefficient of the $\log t$ regressor discriminates the behavior of the dependent variable under the alternative hypothesis of divergence $\mathcal{H}_{A}$, from its behavior under the null hypothesis of convergence $\boldsymbol{H}_{\mathbf{0}}$. The $t$-test statistic follows asymptotically the standard normal distribution, and is constructed using a heteroskedasticity and autocorrelation consistent standard error. ${ }^{7}$ PS call the one-sided $t$-test, the $\log t$ test due to the presence of the $\log t$ regressor in equation

\footnotetext{
${ }^{6}$ Appendix B of PS reports the analytic proof under the convergence hypothesis for this regression equation.

7 Standard errors are estimated using the Newey-West HAC estimator (1987) with the Quadratic Spectral kernel. Bandwidth is set equal to the "optimal" bandwidth which is automatically selected using the parametric methodology
} 
(5). The null hypothesis of convergence is accepted at the $5 \%$ level if the log $t$ test is greater than 1.65. PS argue that discarding some fraction $r$ of the time series data helps to focus attention on what happens as the sample gets larger. Based on simulation experience, they suggest that $r=0.3$ is a good choice in terms of both size and power.

Furthermore, we extend the simulation study of PS in order to investigate how the $\log t$ test behaves (i) under structural breaks, and (ii) in finite samples of different sizes. Our simulations results reported in Table B1 of Appendix B, show that the logt test is robust to the presence of structural breaks. Contrary, our results suggest that the number of observations affects significantly the power performance of the test.

The empirical convergence literature also deals with the possible existence of multiple equilibriums. In that case, rejection of the null hypothesis that all countries in the sample converge does not imply the absence of convergence clubs in the panel. In this study, we implement the club convergence and clustering procedure proposed by PS. We summarize that procedure as follows: (1) Order the N countries with respect to the last-period value of the time series; (2) Form all possible core (club) groups $C_{k}$ by selecting the first $k$ highest countries, with $k=2,3, \ldots, N$. Then, test for convergence using the $\log t_{k}$ test within each subgroup of size $k$. Finally, define the core club $C^{*}$ of size $k^{*}$ as the club for which the maximum computed $\log t_{k^{*}}$ statistic occurs, given that the $\log t_{k}$ statistics supports the convergence hypothesis; (3) From the remaining $N-k^{*}$ countries, add one country at a time to the core club $C^{*}$ and test for convergence through the logt test. If the test strongly supports the convergence hypothesis $(\log t \geq 0)$, then include the country to the group $C^{*}$. Find all

suggested by Andrews (1991). Results obtained using the Bartlett kernel are qualitatively the same and are reported in Appendix A (Table A2). 
countries that, according to the $\log t$ test, converge to the same steady state with the core group $C^{*}$ ; these countries together with the countries of the core group $C^{*}$ form the first convergence club in the panel; (4) Then, for the remaining countries (if any), repeat the procedure described in steps 1 3 to determine the next convergence club, if one exists. Finally, terminate the procedure when the remaining economies fail to converge. However, since the sieve criterion ( $\log t \geq 0$ ) set in step (3) is highly conservative club convergence and clustering procedure tends to find more clubs than the true number. To avoid such overestimation, PS suggest running $\log t$ test regressions across the subgroups to access evidence in support of merging clubs into larger clubs.

\title{
2.2. Data
}

We collect monthly observations of 10 -year sovereign bond yields (in percentage) series for the EA 18 countries over the period March 2002 to December 2015 (i.e. 166 observations) from the ECB Statistical Data Warehouse database. The starting date of the analysis is purely dictated by data availability. Specifically, March 2002 is the earliest date for which sovereign bond yields exist for all EA countries. Estonia is the only EA country for which sovereign bond yields data are not available at all, and thus excluded from our EA country sample. We then convert the 10 -year sovereign bond yields series into spreads by subtracting the German bond yield series from each of the remaining EA17 bond yield series. Figure 1 plots the sovereign bond yield spreads, and Table 1 reports their descriptive statistics.

\author{
[Insert Table 1 around here] \\ [Insert Figure 1 around here]
}


According to Figure 1, it is evident the increase in spreads in the Euro Area countries that suffered from increased sovereign debts since the global financial crisis and the subsequent eurozone debt crisis. ${ }^{8}$ Sovereign bond yield spreads, on average, were the highest for Greece, followed by Latvia, Cyprus, Portugal, Lithuania, Slovenia, Ireland, Italy, Malta and Spain, ranging between 1.16\% to 4.94\% (see Table 1); while spreads for the "safe" EA countries, such as Austria, Belgium, Finland, France and Netherlands were much smaller, ranging between $0.21 \%$ and $0.53 \%$, and were even negative for Luxembourg (see Table 1). Moreover, the increasingly divergence patterns in some EA17 countries is also reflected in the simple dispersion measures of sovereign bond yield spreads reported in Table 1. For instance, the standard deviation of sovereign bond yield spreads in the former group is much higher compared to that of the latter group.

\section{Empirical Results}

Table 2 reports the results of applying the PS convergence and clustering procedure. The first row of Panel A reports the result for testing the hypothesis that all EA17 countries converge to a single steady state; the convergence hypothesis is rejected at 5\% level of significance. All the remaining rows of Panel A show the empirical results obtained from a direct application of the clustering algorithm described above. The algorithm classifies countries in 3 subgroups convergence clubs, with Cyprus, Spain, France, Greece, Ireland, Lithuania, Luxembourg, Latvia, Portugal and Slovenia in the first; Belgium, Italy and Malta in the second; and Austria, Finland, Netherlands and Slovakia in the third club. According to the PS algorithm, there is no country in the EA that fails to converge to any of the existing steady states. Panel B reports the test conducted to determine whether any of the original subgroups reported in Panel A can be merged to form larger convergence clubs. This test suggests

\footnotetext{
${ }^{8}$ We have shown through Monte Carlo Simulations that the $\log t$ test is robust to the presence of structural breaks. The results are reported in Appendix B (Table B1).
} 
that the first and second subgroups can be merged to form a larger convergence club. The second and third subgroup, however, do not contribute to any merging. Hence, subgroup two and subgroup three are taken to form separate convergence clubs. ${ }^{9}$

\section{[Insert Table 2 around here]}

Figure 2 depicts the relative transition curves for the EA17 sovereign bond yield spreads. Visual inspection of these curves enables us to gain some insight on the outcomes of the testing methodology and monitor the convergence of these sovereign bond yield spreads, relatively to the EA17 sample average. In particular, the transition curves report a graphical picture about the tendency of the cluster participants to converge or diverge from above or below 1, which is the convergence path reference point during the period under study. The graphical findings of the transition curves highlight that, despite short-run divergences, there is a long-run tendency towards convergence of EA17 sovereign bond yield spreads, with the exception of Greece and Cyprus, indicating the strong attempts of the countries under investigation to adopt fiscal policies that eventually contribute to a convergence pattern.

\section{[Insert Figure 2 around here]}

\section{Conclusion}

\footnotetext{
${ }^{9}$ In our empirical application we set $r=0.30$ since PS show through Monte Carlo simulations that this is a good choice for empirical application in terms of both size and power. Following reviewer's suggestion we provide results for four more values of $\mathrm{r}(r=0.20,0.23,0.26,0.29)$. We present these results in Appendix A. For values of $r \leq 0.26$ the $\log t$ test suggests that all countries converge to a single steady state. For $r>0.26$ the results are qualitatively the same as those reported in Table 2 for $r=0.30$. However, note that these values are inferior in terms of size and power than $r=$ 0.30 .
} 
The main objective of the paper is to examine the convergence patterns of EA 17 countries' sovereign bond yield spreads (relative to German bund) over the period of March 2002 to December 2015, by employing the convergence algorithm developed by Phillips and Sul (2007). The main results are the following.

First, the empirical results suggest the rejection of full convergence over the 17 countries' sovereign bond yield spreads. According to the literature on the determinants of bond yield spreads, and as explained above, this would suggest that relevance of country-specific factors (and not only international factors) in explaining their behaviour. Therefore, and based on this literature, liquidity and sovereign risk variables have played a significant role in the evolution of EA bond yield spreads, which suggest the relevance of countries' fiscal variables (specially, fiscal deficit and debt to GDP ratios) in determining bond yield differentials. The results justify the need to adopt common fiscal policies among the EA member states.

Second, among the 17 EA countries, three subgroup convergence clubs emerge, with Cyprus, Spain, France, Greece, Ireland, Lithuania, Luxembourg, Latvia, Portugal and Slovenia in the first; Belgium, Italy and Malta in the second; and Austria, Finland, Netherlands and Slovakia in the third club. This result gives an idea of how simplistic is the classification of the EA countries in "core" or "periphery" countries when explaining their divergent behaviour in bond yield spreads.

Third, there is also evidence that the first two clubs could be merged to form a larger convergence club. The second and third subgroup, however, do not contribute to any merging. Hence, subgroup two and subgroup three are taken to form separate convergence clubs. Based on this result, it is relevant to mention the different behaviour that Slovakia, which adopted the euro in 2009, presents compared to the other EA new members, suggesting that the adoption of the common 
currency was not the most relevant variable to explain the convergence process of EA bond yield spreads.

Finally, the transitional curves indicate that, despite short-run divergences, EU17 sovereign bond yield spreads tend to converge over the long, with the exception of those in Greece and Cyprus. This result justifies again the need to adopt common fiscal policies among the EA member states, directed mainly to the reduction of fiscal deficits and debt to GDP ratios in these countries.

\section{Acknowledgements}

We like to thank the editor (Jonathan A. Batten) and an anonymous referee for insightful comments on a previous version of this paper. The usual disclaimer applies. 


\section{References}

Afonso, A., Arghyrou, G. and Kontonikas, A., 2015. The determinants of sovereign bond yield spreads in the EMU. European Central Bank Working Paper Series 1781.

Amisano, G. and Trisani, O., 2011. The euro area sovereign crisis: Monitoring spillovers and contagion. ECB Research Bulletin 14.

Antonakakis, N. and Vergos, K., 2013. Sovereign bond yield spillovers in the Euro zone during the financial and debt crisis. Journal of International Financial Markets, Institutions and Money 26, 258-272.

Andrews, D.W.K.,1991. Heteroskedasticity and autocorrelation consistent covariance matrix estimation. Econometrica 59, 817-858.

Apergis, N., Christou, C. and Miller, S. 2014. Country and industry convergence of equity markets: International evidence from club convergence and clustering. North American Journal of Economics and Finance 29, 36-58.

Apergis, N. and Cooray, A. 2014. Convergence in sovereign debt ratios across heavily indebted EMU countries: evidence from club convergence. Applied Economics Letters 21, 786-788.

Arghyrou, M. and Kontonikas, A., 2012. The EMU sovereign-debt crisis: Fundamentals, expectations and contagion. Journal of International Financial Markets, Institutions and Money 22, 658-677.

Baele, L., Ferrando, A., Hördahl, P., Krylova, E. and Monnet, C., 2004. Measuring European Financial Integration, Oxford Review of Economic Policy 20 (4), 509-530.

Barrios, S., Iversen, P., Lewandowska, M. and Setzer, R., 2009. Determinants of intra-euro área government bond spreads during the financial crisis. European Economy- Economic Papers 388, European Commission.

Barro, R. and Sala-i-Martin, X., 1992. Convergence. Journal of Political Economy 100, 233-251.

Baum, C. and Barkoulas, J., 2006. Dynamics of intra-ems interest rate linkages. Journal of Money, Credit, and Banking 38, 469-482. 
Baumol, W.J., 1986. Productivity growth, convergence and welfare: what the long-run data show. American Economic Review 76, 1072-1085.

Beirne, J. and Fratzscher, M., 2013. The pricing of sovereign risk and contagion during the European sovereign debt crisis. Journal of International Money and Finance 34:60-82.

Bernoth, K. and Erdogan, B., 2012. Sovereign bond yield spreads: A time-varying coefficient approach. Journal of International Money and Finance 31, 639-656.

Calice, G., Chen, J. And Williams, J., 2012. Liquidity spillovers in sovereign bond and CDS markets: An analysis of the Eurozone Sovereign Debt Crisis. Journal of Economic Behavior and Organization $85,122-143$.

Campbell, J. and Shiller, J.R., 1991. Yield spreads and interest rate movements: a bird's eye view, Review of Economic Studies 58, 495-514.

Caporale, G., Erdogan, B. and Kuzin, V. 2015. Testing stock market convergence: a non-linear factor approach. Empirica 42, 481-498.

Codogno, L., Favero, C. and Missale, A., 2003. Yield spreads on EMU government bonds. Economic Policy 18, 505-532.

Côté, D. and Graham, C., 2004. Convergence of Government Bond Yield in the Euro Zone: the Role of Policy Harmonization. Bank of Canada Working Paper, 2004-23.

Dickey, D.A. and Fuller, W.A., 1979. Distribution of the estimators for autoregressive time series with a unit root. Journal of American Statistical Society 75, 427-431.

European Central Bank, 2003. ECB Monthly Bulletin, November.

Favero, C., Pagano, M. and von Thadden, E.L., 2010. How does liquidity affect government bond yields? Journal of Financial and Quantitative Analysis 45, 107-134.

Favero, C., and Missale, A., 2012. Sovereign spreads in the Eurozone: which prospects for a Eurobond? Economic Policy 27, 231-273. 
Friedman, M., 1992. Do old fallacies ever die? Journal of Economics Literature 30, 2129-2132.

Frömmel, M. and Kruse, R., 2009. Interest rate convergence in the EMS prior to European Monetary Union. Journal of Policy Modeling 37 (6), 990-1004.

Geyer, A., Kossmeier, S. and Pichler, S., 2004. Measuring systematic risk in EMU government yield spreads. Review of Finance 8, 171-197.

Gomez-Puig, M. and Sosvilla-Rivero, S., 2014. Causality and contagion in EMU sovereign debt markets. International Review of Economics and Finance 33:12-27.

Laopodis, N., 2008. Government bond market integration within European Union. International Research Journal of Finance and Economics 19, 56-76.

Leschinski, C., and Bertram, P., 2013. Contagion dynamics in EMU government bond spreads. Hannover Economics Papers 515.

Mankiw, G., Romer, P. And Weil, D.N., 1992. A contribution to the empirics of economic growth. Quarterly Journal of Economics 107, 407-437.

Masson, P., 1999. The Asian Financial Crisis: Causes, Contagion and Consequences, chapter contagion: monsoonal effects, spillovers, and jumps between multiple equilibria. Cambridge University Press, Cambridge, UK.

Metiu, N., 2012. Sovereign risk contagion in the Eurozone. Economics Letters 117:35-38.

Newey, W.K, West, K., 1987. A simple positive semi-definite, heteroskedasticity and autocorrelation consistent covariance matrix. Econometrica 55, 703-708.

Oliveira, L., Curto, J.D. and Nunes, J.P., 2012. The determinants of sovereign credit spread changes in the Euro-zone. Journal of International Financial Markets, Institutions and Money 22, 278-304.

Phillips, P.C.B. and Perron, P., 1988. Testing for a unit root in time series regression. Biometrika 75, 335-346. 
Phillips, P. C. B., and D. Sul., 2007. Transition Modeling and Econometric Convergence Tests. Econometrica 75 (6), 1771-1855.

Pozzi, L. and Wolswijk, G., 2012. The time-varying integration of euro area government bond markets. European Economic Review 56 (1), 36-53.

Rose, A., 1988. Is the real interest rate stable? Journal of Finance 43, 1095-112.

Sgherri, S. and Zoli, E., 2009. Euro area sovereign risk during the crisis. IMF Working Paper $09 / 222$.

Sibbertsen, P., Wegener, C. and Basse, T., 2014. Testing for a break in the persistence in yield spreads of EMU government bonds. Journal of Banking and Finance 41, 109-118.

Siklos, P., 2010. Meeting Maastricht: Nominal convergence of the new member states forward EMU. Economic Modelling 27, 507-515.

Siklos, P. and Wohar, M., 1997. Convergence in interest rates and inflation rates across countries and over time. Review of International Economics 5, 129-141. 
Figure 1: EU17 countries' sovereign bond yield spreads

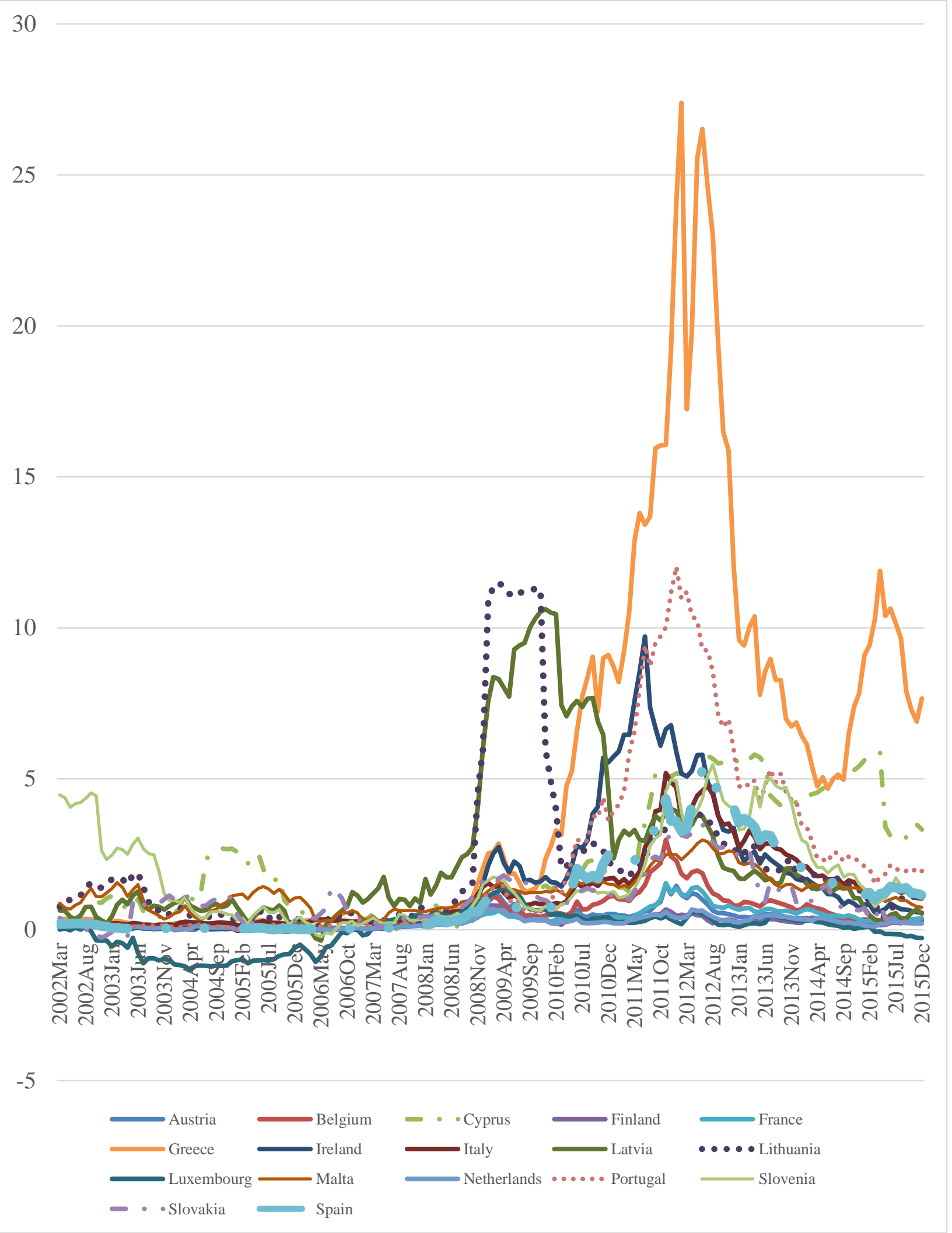


Figure 2: EA17 - Relative transition curves

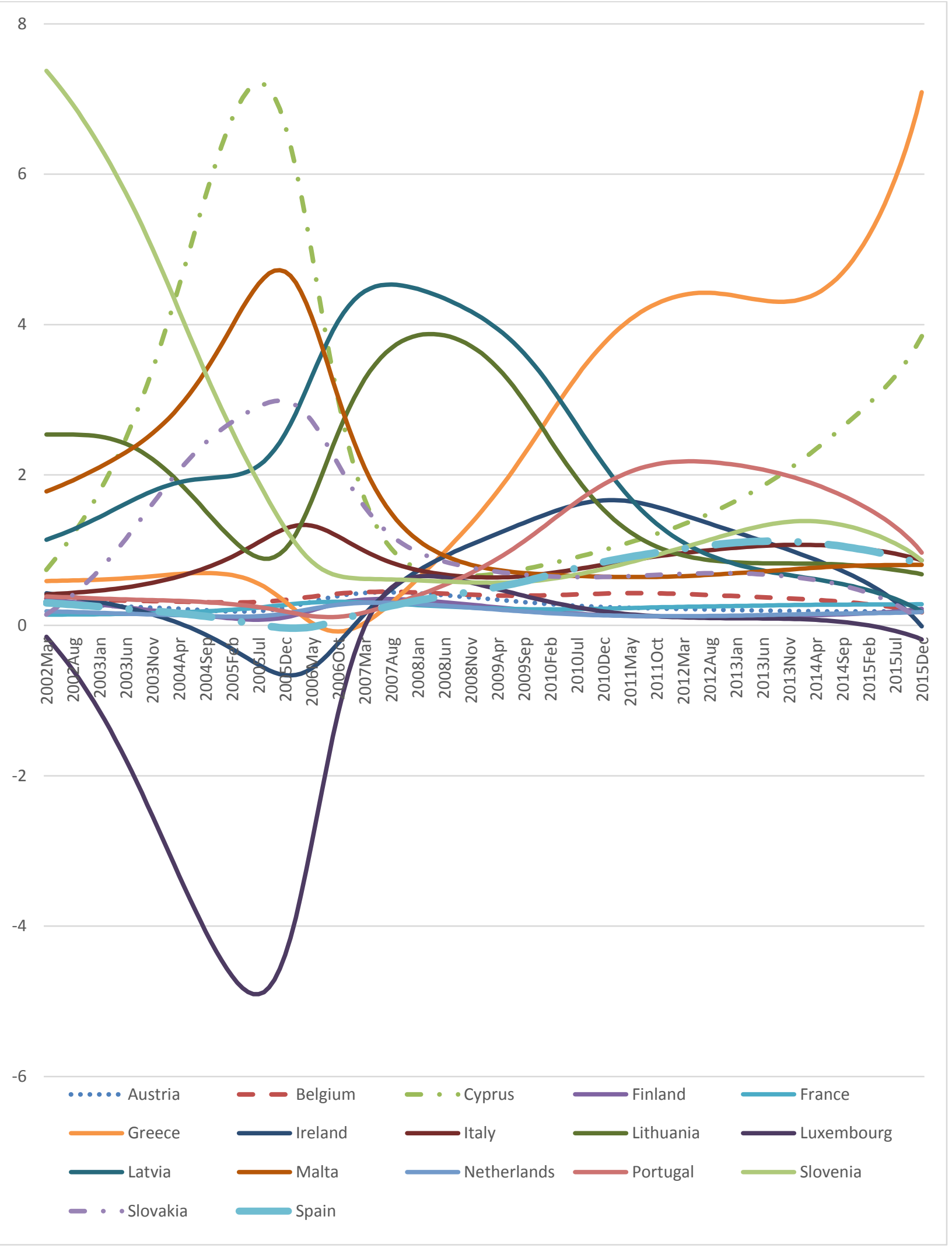


Table 1: Descriptive statistics of EA17 sovereign bond yield spreads

\begin{tabular}{lrrrrrrr}
\hline & Mean & Stdev & Min & Max & Skewness & Kurtosis & JB \\
\hline AUSTRIA & 0.34 & 0.31 & 0 & 1.49 & 1.40 & 4.88 & 78.56 \\
BELGIUM & 0.53 & 0.55 & 0.03 & 2.97 & 1.75 & 6.29 & 159.19 \\
CYPRUS & 2.29 & 1.93 & -0.12 & 5.88 & 0.63 & 1.89 & 19.36 \\
FINLAND & 0.22 & 0.18 & -0.05 & 0.8 & 0.84 & 3.78 & 23.92 \\
FRANCE & 0.34 & 0.33 & 0.02 & 1.54 & 1.41 & 4.99 & 82.36 \\
GREECE & 4.94 & 6.36 & 0.13 & 27.39 & 1.56 & 5.04 & 95.71 \\
IRELAND & 1.57 & 2.12 & -0.05 & 9.71 & 1.63 & 4.92 & 98.95 \\
ITALY & 1.23 & 1.24 & 0.14 & 5.19 & 1.35 & 4.05 & 57.68 \\
LATVIA & 2.40 & 2.73 & -0.36 & 10.61 & 1.69 & 4.76 & 100.11 \\
LITHUANIA & 2.14 & 2.69 & 0.01 & 11.48 & 2.51 & 8.81 & 407.50 \\
LUXEMBOURG & -0.01 & 0.64 & -1.33 & 1.41 & -0.41 & 2.49 & 6.47 \\
MALTA & 1.23 & 0.62 & 0.28 & 2.97 & 0.76 & 3.23 & 16.20 \\
NETHERLANDS & 0.21 & 0.18 & -0.02 & 0.69 & 0.74 & 2.75 & 15.41 \\
PORTUGAL & 2.24 & 2.99 & 0 & 12.03 & 1.61 & 4.71 & 92.29 \\
SLOVAKIA & 1.00 & 0.86 & -0.27 & 3.5 & 1.10 & 3.80 & 37.62 \\
SLOVENIA & 1.75 & 1.52 & -0.23 & 5.47 & 0.85 & 2.44 & 22.22 \\
SPAIN & 1.16 & 1.38 & 0 & 5.55 & 1.25 & 3.66 & 46.02 \\
\hline
\end{tabular}

Table 2: EA17 - Club convergence

\begin{tabular}{|c|c|c|c|}
\hline Subgroup & Countries & b coefficient & $\log t$-statistic \\
\hline \multicolumn{4}{|c|}{ Panel A: Club Convergence } \\
\hline Full sample & $\begin{array}{l}\text { Austria, Belgium, Cyprus, Spain, Finland, France, Greece, } \\
\text { Ireland, Italy, Lithuania, Luxembourg, Latvia, Malta, } \\
\text { Netherlands, Portugal, Slovenia, Slovakia }\end{array}$ & -0.126 & $-3.354^{*}$ \\
\hline $1^{\text {st }}$ subgroup & $\begin{array}{l}\text { Cyprus, Spain, France, Greece, Ireland, Lithuania, } \\
\text { Luxembourg, Latvia, Portugal, Slovenia }\end{array}$ & 0.565 & 2.672 \\
\hline $2^{\text {nd }}$ subgroup & Belgium, Italy, Malta & 0.050 & 0.308 \\
\hline $3^{\text {rd }}$ subgroup & Austria, Finland, Netherlands, Slovakia & 0.504 & 0.750 \\
\hline Non - converging & --1-1--1--- & & \\
\hline \multicolumn{4}{|c|}{ Panel B: Subgroup Merging } \\
\hline $\begin{array}{l}1^{\text {st }} \text { subgroup }+2^{\text {nd }} \\
\text { subgroup }\end{array}$ & & 0.147 & 2.792 \\
\hline $\begin{array}{l}2^{\text {nd }} \text { subgroup }+3^{\text {rd }} \\
\text { subgroup }\end{array}$ & & -0.634 & $-2.134^{*}$ \\
\hline
\end{tabular}

\section{Appendix $A$}


Table A1: EA17 - Convergence test results for different values of $r$ - the case of the Quadratic Spectral kernel function.

\begin{tabular}{|c|c|c|c|}
\hline Subgroup & Countries & b coefficient & $\log t$-statistic \\
\hline \multicolumn{4}{|l|}{$r-0.20$} \\
\hline Full sample & $\begin{array}{l}\text { Austria, Belgium, Cyprus, Spain, Finland, France, Greece, } \\
\text { Ireland, Italy, Lithuania, Luxembourg, Latvia, Malta, } \\
\text { Netherlands, Portugal, Slovenia, Slovakia }\end{array}$ & 0.419 & 1.522 \\
\hline \multicolumn{4}{|l|}{$\mathrm{r}=0.23$} \\
\hline Full sample & $\begin{array}{l}\text { Austria, Belgium, Cyprus, Spain, Finland, France, Greece, } \\
\text { Ireland, Italy, Lithuania, Luxembourg, Latvia, Malta, } \\
\text { Netherlands, Portugal, Slovenia, Slovakia }\end{array}$ & 0.326 & 1.640 \\
\hline \multicolumn{4}{|l|}{$\mathrm{r}=0.26$} \\
\hline Full sample & $\begin{array}{l}\text { Austria, Belgium, Cyprus, Spain, Finland, France, Greece, } \\
\text { Ireland, Italy, Lithuania, Luxembourg, Latvia, Malta, } \\
\text { Netherlands, Portugal, Slovenia, Slovakia }\end{array}$ & 0.134 & 2.381 \\
\hline \multicolumn{4}{|l|}{$\mathrm{r}=0.29$} \\
\hline Full sample & $\begin{array}{l}\text { Austria, Belgium, Cyprus, Spain, Finland, France, Greece, } \\
\text { Ireland, Italy, Lithuania, Luxembourg, Latvia, Malta, } \\
\text { Netherlands, Portugal, Slovenia, Slovakia }\end{array}$ & -0.072 & $-2.632^{*}$ \\
\hline $1^{\text {st }}$ subgroup & $\begin{array}{l}\text { Cyprus, Spain, France, Greece, Ireland, Italy, Lithuania, } \\
\text { Luxembourg, Latvia, Portugal, Slovenia }\end{array}$ & 0.513 & 4.554 \\
\hline $2^{\text {nd }}$ subgroup & Belgium, Malta & 0.522 & 2.640 \\
\hline $3^{\text {rd }}$ subgroup & Austria, Finland, Netherlands, Slovakia & 0.581 & 0.898 \\
\hline $\begin{array}{l}1^{\text {st }} \text { subgroup }+2^{\text {nd }} \\
\text { subgroup }\end{array}$ & & 0.205 & 4.531 \\
\hline $\begin{array}{l}2^{\text {nd }} \text { subgroup }+3^{\text {rd }} \\
\text { subgroup }\end{array}$ & & -0.214 & $-1.953^{*}$ \\
\hline \multicolumn{4}{|l|}{$\mathrm{r}=0.30$} \\
\hline Full sample & $\begin{array}{l}\text { Austria, Belgium, Cyprus, Spain, Finland, France, Greece, } \\
\text { Ireland, Italy, Lithuania, Luxembourg, Latvia, Malta, } \\
\text { Netherlands, Portugal, Slovenia, Slovakia }\end{array}$ & -0.126 & $-3.354^{*}$ \\
\hline $1^{\text {st }}$ subgroup & $\begin{array}{l}\text { Cyprus, Spain, France, Greece, Ireland, Lithuania, } \\
\text { Luxembourg, Latvia, Portugal, Slovenia }\end{array}$ & 0.565 & 2.672 \\
\hline $2^{\text {nd }}$ subgroup & Belgium, Italy, Malta & 0.050 & 0.308 \\
\hline $3^{\text {rd }}$ subgroup & Austria, Finland, Netherlands, Slovakia & 0.504 & 0.750 \\
\hline $\begin{array}{l}1^{\text {st }} \text { subgroup }+2^{\text {nd }} \\
\text { subgroup }\end{array}$ & & 0.147 & 2.792 \\
\hline $\begin{array}{l}2^{\text {nd }} \text { subgroup }+3^{\text {rd }} \\
\text { subgroup }\end{array}$ & & -0.634 & $-2.134^{*}$ \\
\hline
\end{tabular}

Notes: “*” denotes the rejection of the null hypothesis of convergence at the $5 \%$ significance level. Standard errors are estimated using the Newey-West HAC estimator (1987) with the Quadratic Spectral kernel. Bandwidth is set equal to the "optimal" bandwidth which is automatically selected using the parametric methodology suggested by Andrews (1991) 
Table A2: EA17 - Convergence test results for different values of $\mathrm{r}$ - the case of the Bartlett kernel function.

\begin{tabular}{|c|c|c|c|}
\hline Subgroup & Countries & b coefficient & $\log t$-statistic \\
\hline \multicolumn{4}{|l|}{$\mathrm{r}-0.20$} \\
\hline Full sample & $\begin{array}{l}\text { Austria, Belgium, Cyprus, Spain, Finland, France, Greece, } \\
\text { Ireland, Italy, Lithuania, Luxembourg, Latvia, Malta, } \\
\text { Netherlands, Portugal, Slovenia, Slovakia }\end{array}$ & 0.419 & 1.247 \\
\hline \multicolumn{4}{|l|}{$\mathrm{r}=0.23$} \\
\hline Full sample & $\begin{array}{l}\text { Austria, Belgium, Cyprus, Spain, Finland, France, Greece, } \\
\text { Ireland, Italy, Lithuania, Luxembourg, Latvia, Malta, } \\
\text { Netherlands, Portugal, Slovenia, Slovakia }\end{array}$ & 0.326 & 1.154 \\
\hline \multicolumn{4}{|l|}{$\mathrm{r}=0.26$} \\
\hline Full sample & $\begin{array}{l}\text { Austria, Belgium, Cyprus, Spain, Finland, France, Greece, } \\
\text { Ireland, Italy, Lithuania, Luxembourg, Latvia, Malta, } \\
\text { Netherlands, Portugal, Slovenia, Slovakia }\end{array}$ & 0.134 & 1.506 \\
\hline \multicolumn{4}{|l|}{$\mathrm{r}=0.29$} \\
\hline Full sample & $\begin{array}{l}\text { Austria, Belgium, Cyprus, Spain, Finland, France, Greece, } \\
\text { Ireland, Italy, Lithuania, Luxembourg, Latvia, Malta, } \\
\text { Netherlands, Portugal, Slovenia, Slovakia }\end{array}$ & -0.072 & $-3.168^{*}$ \\
\hline $1^{\text {st }}$ subgroup & $\begin{array}{l}\text { Cyprus, Spain, France, Greece, Ireland, Italy, Lithuania, } \\
\text { Luxembourg, Latvia, Portugal, Slovenia }\end{array}$ & 0.513 & 2.727 \\
\hline $2^{\text {nd }}$ subgroup & Belgium, Malta & 0.522 & 1.708 \\
\hline $3^{\text {rd }}$ subgroup & Austria, Finland, Netherlands, Slovakia & 0.581 & -1.540 \\
\hline $\begin{array}{l}1^{\text {st }} \text { subgroup }+2^{\text {nd }} \\
\text { subgroup }\end{array}$ & & 0.205 & 3.700 \\
\hline $\begin{array}{l}2^{\text {nd }} \text { subgroup }+3^{\text {rd }} \\
\text { subgroup }\end{array}$ & & -0.214 & $-1.876^{*}$ \\
\hline \multicolumn{4}{|l|}{$\mathrm{r}=\mathbf{0 . 3 0}$} \\
\hline Full sample & $\begin{array}{l}\text { Austria, Belgium, Cyprus, Spain, Finland, France, Greece, } \\
\text { Ireland, Italy, Lithuania, Luxembourg, Latvia, Malta, } \\
\text { Netherlands, Portugal, Slovenia, Slovakia }\end{array}$ & -0.126 & $-3.168^{*}$ \\
\hline $1^{\text {st }}$ subgroup & $\begin{array}{l}\text { Cyprus, Spain, France, Greece, Ireland, Lithuania, } \\
\text { Luxembourg, Latvia, Portugal, Slovenia }\end{array}$ & 0.565 & 1.557 \\
\hline $2^{\text {nd }}$ subgroup & Belgium, Italy, Malta & 0.050 & -0.067 \\
\hline $3^{\text {rd }}$ subgroup & Austria, Finland, Netherlands, Slovakia & 0.504 & 0.698 \\
\hline $\begin{array}{l}1^{\text {st }} \text { subgroup }+2^{\text {nd }} \\
\text { subgroup }\end{array}$ & & 0.147 & 0.932 \\
\hline $\begin{array}{l}2^{\text {nd }} \text { subgroup }+3^{\text {rd }} \\
\text { subgroup }\end{array}$ & & -0.634 & $-1.669 *$ \\
\hline
\end{tabular}

Notes: “*” denotes the rejection of the null hypothesis of convergence at the $5 \%$ significance level. Standard errors are estimated using the Newey-West HAC estimator (1987) with the Bartlett kernel. Bandwidth is set equal to the "optimal" bandwidth which is automatically selected using the parametric methodology suggested by Andrews (1991). 


\section{Appendix B}

In order provide some evaluation on the performance of the logt test in the presence of breaks we carried out a small simulation exercise. Following Phillips and Sul (2007), we adopt the data generating process (DGP):

$y_{i t}=\delta_{i t} \mu_{t}, \mu_{t}=\theta_{0}+\theta_{1} \mathbb{1}\left\{t>t_{1}\right\}+\theta_{2} \mathbb{1}\left\{t>t_{2}\right\}+\mu_{t-1}+e_{t}, e_{t} \sim \operatorname{iidN}(0,1)$

$\delta_{i t}=\delta_{i}+\delta_{i t}^{0}, \delta_{i t}^{0}=\rho_{i} \delta_{i t-1}^{0}+\varepsilon_{i t}, \varepsilon_{i t} \sim \operatorname{iidN}\left(0, \sigma_{i}^{2} L(t+1)^{-2} t^{-2 \alpha}\right)$, where $L(t)=\log t, \rho_{i} \sim U[0,0.9], \sigma_{i} \sim U[0.02,0.28]$.

The DGP follows the time-varying representation (Eq.1) for $y_{i t}$ adopted by Phillips and Sul (2007). As was described in the methodology section, transition dynamics are captured by the idiosyncratic components $\delta_{i t}$. The form of $\delta_{i t}$ in our DGP is in line with Eq.3, and thus ensures convergence if and only if $\delta_{i}=\delta$ and $\alpha \geq 0$ (page 9). On the other hand, divergence occurs if and only if $\delta_{i} \neq \delta$ or $\alpha<0$ (page 9). Furthermore, our DGP allows us to introduce breaks in the transition dynamics. Specifically, when $\theta_{1}=\theta_{2}=0$, the permanent component $\mu_{t}$, follows a random walk with drift but no breaks. In the case $\theta_{1} \neq 0, \theta_{2}=0$, there is a break in drift (mean) at $t_{1}$. We also consider the case with two breaks in drift, which occurs when $\theta_{1} \neq 0$ and $\theta_{2} \neq 0$. The value of the coefficient $\theta_{0}$ does not affect simulation performance and results and a is set to be zero.

To check the size and the power of the test we set $\delta_{i}=1$ and $\delta_{i} \sim U[1,2]$, respectively.

For all cases, we set $\alpha=0.01,0.05,0.1,0.2, T=83,166$ and $N=17$.

To investigate the performance of the logt test we consider the following three DGPs:

DGP1 (No structural breaks): $\theta_{1}=\theta_{2}=0$.

DGP2 (One structural break): $\theta_{1}=1, t_{1}=T / 2$.

DGP3 (Two structural breaks: $\theta_{1}=1, \theta_{2}=-0.5, t_{1}=T / 2, t_{2}=(3 T / 4)$. 
The number of replications was 2000.

Table B1 shows the simulations results for the three DGPs described above. The nominal size is fixed to be $5 \%$. The power of the test is reported without size adjustment.

The size of the test does not depend on the values of $\alpha$ and T. Most importantly, the size is not affected by the presence of structural breaks.

The empirical power is not significantly affected by the values of $\alpha$, especially for $T=166$.

Contrary, our results suggest that sample size affects the power performance of the test. For example, in the case of DGP1 and $\alpha=0.01$, power is reduced from 0.97 for $\mathrm{T}=166$ to 0.72 for $\mathrm{T}=83$. Most importantly, the $\log t$ test appears to be robust to the presence of structural breaks.

Table B1: Empirical size and power of the $\log t$ test (5\% nominal size)

\begin{tabular}{lllllllll}
\hline \multicolumn{9}{c}{$\mathrm{T}=166$} \\
\hline \\
\hline
\end{tabular}

Notes: In all simulations the number of the cross section units is set $\mathrm{N}=17$. 